\title{
Single-sample diagnosis of recent rubella by fractionation of antibody on Sephadex G-200 column
}

\author{
J. D. GUPTA, V. PETERSON, MARILYN STOUT, AND A. M. MURPHy
}

From the Children's Medical Research Foundation, Royal Alexandra Hospital for Children, Camperdown, Sydney, and the Institute of Clinical Pathology and Medical Research, Lidcombe

SYNOPSIS To facilitate the diagnosis of recent rubella infection, rubella haemagglutination inhibiting antibody has been determined in four fractions obtained by Sephadex G-200 gel filtration of samples of serum. All the 21 samples collected at the convalescent stage of the disease had varying proportions of haemagglutination inhibiting antibody in fraction 1, representing the major portion of IgM antibody whereas all but three out of 22 sera from persons with no history of recent rubella had negative titres in this fraction. The haemagglutination inhibiting titres in the three positive sera in the second group was very low as compared to the other fractions. Fractionation of sera on a Sephadex G-200 column coupled with the rubella haemagglutination inhibition test can, therefore, be used to diagnose recent rubella infection.

The serological diagnosis of rubella infection depends on the demonstration of a rising titre of antibody which is usually measured by the haemagglutination inhibition test. If an 'acute phase' serum is not collected within four or five days of the onset of symptoms, a rising titre frequently cannot be shown. In such cases the demonstration of the presence of rubella-specific IgM antibody is of great assistance because these globulins appear in the early response to primary antigenic stimulus and then fall away to low undetectable levels within a few weeks. Also, the demonstration of specific IgM in the newborn is considered to indicate intrauterine infection (Alford, 1965). However, the methods available for estimating specific IgM are not particularly satisfactory for routine work: reduction of antibody titre after treatment with mercapto-ethanol (Banatvala, Best, Kennedy, Smith, and Spence, 1967) because of insensitivity and unreliability; the immunofluorescence technique (Baublis and Brown, 1968) due to non-specific fluorescence and the rigorous efforts needed to eliminate possible sources of error; and separation of IgM antibody by sucrose density-gradient centrifugation (Vesikari and Vahery, 1968; Best, Banatvala, and Watson, 1969) because of the more specialized nature of the technique, and the lack of necessary facilities in many laboratories.

Utilizing the technique of gel filtration on a Sephadex G-200 column, IgM antibody, free of IgA and IgG, can be separated into a fraction representReceived for publication 19 November 1970. ing the ascending limb of the first peak, and can then be treated for rubella haemagglutination inhibiting antibody. Using this procedure, all the sera collected during the early convalescent phase (up to 14 days after the appearance of the rash) were found to contain a considerable amount of IgM antibody which gradually diminished to lower levels within a month after infection. No IgM antibody or very little compared with IgG antibody was found in the corresponding fraction in sera of persons with a high rubella haemagglutination inhibiting titre but with no history of recent rubella infection. The very simple procedure of fractionation of sera on Sephadex G-200 column, coupled with the rubella haemagglutination inhibition test can, therefore, be utilized as a diagnostic tool in determining recent rubella infection.

\section{Materials and Methods}

\section{SERUM SAMPLES}

Twenty-one samples of convalescent serum from 17 adult women were obtained at various times after the onset of rubella rash. Clinical rubella was confirmed in all these patients by laboratory findings of sero-conversion in paired sera. Sera were also obtained from 21 adults who possessed rubella haemagglutination inhibiting antibody, but gave no history of recent rubella infection. They were mostly laboratory personnel or pregnant women who had been tested for rubella immunity. Also included in 
this group is a serum specimen with no haemagglutination inhibiting antibody.

\section{FRACTIONATION OF SERA}

All sera were fractionated in a $2.5 \times 45 \mathrm{~cm}$ waterjacketed column (Pharmacia) using a bed height of about $40 \mathrm{~cm}$ of Sephadex G-200 gel. Generally, $3 \mathrm{ml}$ of sera was passed through the column and $3 \mathrm{ml}$ fractions were collected. The sera were eluted by veronal buffer (complement-fixation diluent tablets, Oxoid) at $p \mathrm{H} 7.0$ to which $1 \%$ glucose and $0.01 \%$ sodium azide were added. The optical density of the eluted fractions was read at $280 \mathrm{~m} \mu$. The eluates of the tubes in the ascending and descending portions of the first peak were pooled and designated fractions 1 and 2 respectively; similarly the corresponding portions of the second peak were pooled as fractions 3 and 4 . Each fraction was then adjusted to five times the original volume of serum either by adding more buffer or concentrating by pervaporation as needed.

\section{HAEMAGGLUTINATION INHIBITION TEST}

The fractions collected as described above were used for rubella antibody determination by a microhaemagglutination-inhibition test (Stewart, Parkman, Hopp, Douglas, Hamilton, and Meyer, 1967). Heparin-manganous chloride, however, was used for removal of non-specific inhibitors instead of kaolin. In preliminary experiments, it was found that kaolin removes a considerable amount of antibody, especially of the IgM type, from the fractionated sera. To $0.2 \mathrm{ml}$ of each fraction was added $0.1 \mathrm{ml}$ of a $1: 1$ mixture of heparin (700 units $/ \mathrm{ml})$ and $0.2 \mathrm{M}$ manganous chloride and incubated at $4^{\circ} \mathrm{C}$ for 20 minutes with intermittent shaking. Then $0.1 \mathrm{ml}$ of $25 \%$ pigeon erythrocytes was added and the mixture held for one hour at $4^{\circ} \mathrm{C}$ with constant shaking. The supernatant, now representing a 1:10 dilution with respect to the original serum, was heated for 30 minutes at $56^{\circ} \mathrm{C}$ and then tested for haemagglutination inhibition, using 4 units of rubella haemagglutinating antigen (Flow Laboratories, Rockville, Maryland) and $0.16 \%$ pigeon erythrocytes. The antibody titre was expressed as the reciprocal of that dilution of serum which completely inhibited haemagglutination.

\section{Results}

The distribution of antibody in individual tubes obtained by fractionation of sera from persons with a confirmed history of rubella is shown in Figures 1, 2, and 3. It can be seen that haemagglutinationinhibiting antibody was present in tubes under the ascending part of the first peak only in the case of serum obtained from a patient with confirmed. recent rubella and is absent in the corresponding tubes in the sera from a subject with no history of rubella and from one who had confirmed rubella af year ago. In subsequent experiments, tubes were $\frac{\bar{m}}{\bar{N}}$ therefore, pooled as in Fig. 1 to obtain four fractions from each separated serum.

The haemagglutination inhibition titres of the diff $s$ erent fractions obtained by Sephadex G-200 geb filtration from the convalescent sera are shown in Table I. In all the sera haemagglutination inhibiting $\vec{\omega}$ antibody was present in fraction 1 . The earlier the serum was collected after the onset of illness, the

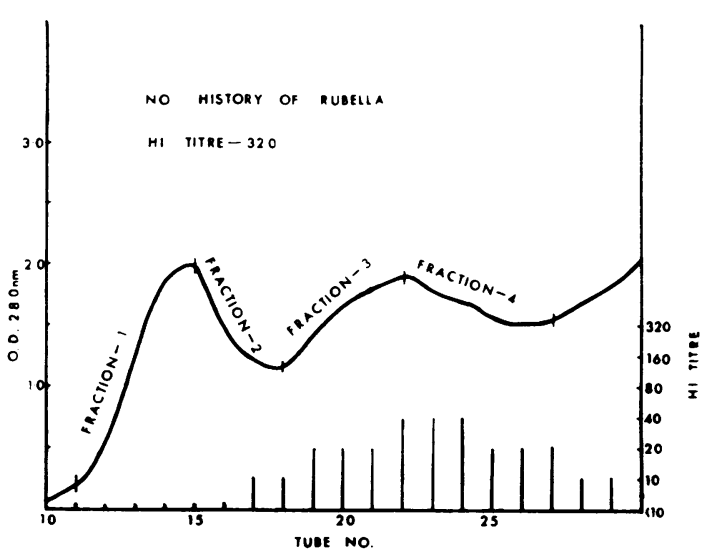

Fig. 1 Rubella haemagglutination-inhibition titre of individual tubes obtained by Sephadex G-200 fractionation of serum from a person with no history of rubella.

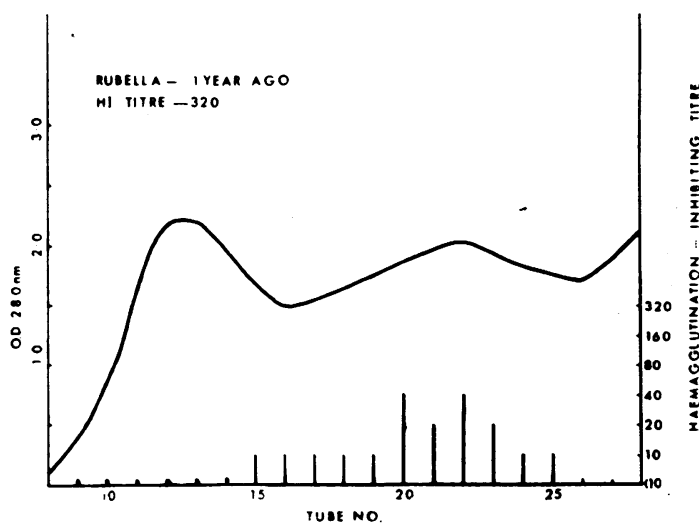

Fig. 2 Rubella haemagglutination-inhibition titre of individual tubes obtained by Sephadex G-200 fractionatio of serum from a person who had confirmed rubella a year ago. 


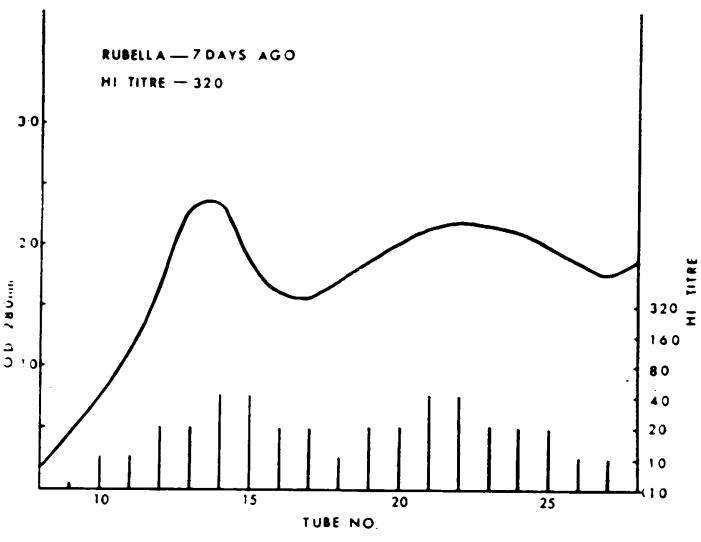

Fig. 3 Rubella haemagglutination-inhibition titre of individual tubes obtained by Sephadex G-200 fractionation of serum from a patient who had confirmed rubella.

higher was the proportion of antibody titre in this fraction. In general, the antibody titre was high in fraction 1 in samples taken within two weeks of the appearance of rash, gradually decreasing to much lower levels thereafter. In contrast, the haemagglutination inhibition titres in fractions 3 and 4 (IgA and IgG) were comparatively low in very early convalescent sera, gradually rising to higher values in the late convalescent sera. Fraction 2 probably represents a mixture of IgM, IgA, and IgG antibody.

\begin{tabular}{|c|c|c|c|c|c|c|}
\hline \multirow{2}{*}{$\begin{array}{l}\text { Patient } \\
\text { No. }\end{array}$} & \multirow{2}{*}{$\begin{array}{l}\text { No. of } \\
\text { Days after } \\
\text { Rash }\end{array}$} & \multicolumn{5}{|c|}{ Haemagglutination-inhibition Titre } \\
\hline & & Serum & Fr 1 & Fr 2 & Fr 3 & Fr 4 \\
\hline 1 & 11 & 640 & 320 & 320 & 160 & 160 \\
\hline \multirow[t]{2}{*}{2} & 15 & 160 & 20 & 40 & 40 & 40 \\
\hline & 25 & 320 & 10 & 40 & 80 & 80 \\
\hline \multirow[t]{2}{*}{3} & 7 & 320 & 160 & 80 & 160 & 80 \\
\hline & 30 & 320 & 20 & 80 & 80 & 80 \\
\hline 4 & 8 & 640 & 160 & 160 & 160 & 160 \\
\hline 5 & 16 & 320 & 40 & 40 & 80 & 160 \\
\hline 6 & 26 & 320 & 40 & 80 & 160 & 160 \\
\hline 7 & Not known & 640 & 80 & 40 & 80 & 80 \\
\hline 8 & 15 & 320 & 40 & 20 & 40 & 40 \\
\hline 9 & 0 & 40 & 40 & 10 & $<10$ & $<10$ \\
\hline \multirow[t]{2}{*}{10} & 5 & 160 & 40 & 20 & 10 & $<10$ \\
\hline & 12 & 640 & 80 & 40 & 160 & 320 \\
\hline 11 & 16 & 320 & 40 & 40 & 160 & 160 \\
\hline 12 & 9 & 320 & 40 & 20 & 40 & 40 \\
\hline 13 & Not known & 320 & 80 & 80 & 80 & 40 \\
\hline 14 & 6 & 640 & 160 & 40 & 80 & 40 \\
\hline & 13 & 640 & 80 & 80 & 80 & 80 \\
\hline 15 & 14 & 160 & 40 & 40 & 80 & 40 \\
\hline 16 & 6 & 640 & 160 & 40 & 80 & 40 \\
\hline 17 & 46 & 640 & 10 & 40 & 160 & 80 \\
\hline
\end{tabular}

Table I Haemagglutination-inhibition titres of convalescent sera and their fractions (Fr) obtained by Sephadex G-200 gel filtration
The haemagglutination inhibition titre of similar fractions from the sera of persons with no history of recent rubella infection are shown in Table II.

\begin{tabular}{lcrrrr}
\hline \multirow{2}{*}{$\begin{array}{l}\text { Sample } \\
\text { No. }\end{array}$} & \multicolumn{5}{l}{ Haemagglutination-inhibition Titre } \\
\cline { 2 - 6 } & Serum & Fr I & Fr 2 & Fr 3 & Fr 4 \\
\hline 1 & 640 & $<10$ & 20 & 80 & 160 \\
2 & 160 & $<10$ & 10 & 20 & 40 \\
3 & 80 & $<10$ & 10 & 20 & 20 \\
4 & 320 & $<10$ & 20 & 160 & 40 \\
5 & 1,280 & 40 & 80 & 320 & 640 \\
6 & 1,280 & $<10$ & 40 & 160 & 320 \\
7 & 1,280 & 20 & 80 & 640 & 640 \\
8 & 2,560 & $<10$ & 80 & 640 & 1,280 \\
9 & 160 & $<10$ & 10 & 40 & 40 \\
10 & 640 & $<10$ & 20 & 80 & 80 \\
11 & 640 & $<10$ & 20 & 80 & 160 \\
12 & 320 & $<10$ & 20 & 80 & 160 \\
13 & 1,280 & $<10$ & 20 & 160 & 320 \\
14 & 1,280 & $<10$ & 40 & 320 & 640 \\
15 & 1,280 & $<10$ & 40 & 320 & 320 \\
16 & 80 & $<10$ & $<10$ & 20 & 20 \\
17 & $<10$ & $<10$ & $<10$ & $<10$ & $<10$ \\
18 & 1,280 & $<10$ & 20 & 160 & 160 \\
19 & 640 & $<10$ & 40 & 160 & 160 \\
20 & 640 & 10 & 20 & 160 & 320 \\
21 & 640 & $<10$ & 40 & 160 & 160 \\
22 & 80 & $<10$ & 10 & 20 & 20 \\
\hline
\end{tabular}

Table II Haemagglutination-inhibition titres of different fractions (Fr) from the sera of persons with no recent history of rubella (immune group)

These samples include the sera of three patients (nos. 4, 12, 20) who had proven rubella several months previously. In almost all the sera, the first fraction had no haemagglutination inhibiting antibody, whereas fractions 3 and 4 had high titres, with intermediate values in the second fraction. Only in three of the 22 samples was haemagglutination inhibiting antibody detected in the first fraction but even then the titres were very low compared to those of fractions 3 and 4, possibly due to spill over from these high antibody fractions. No antibody was found in any of the fractions from a serum which had a negative haemagglutination inhibition titre.

\section{Discussion}

The haemagglutination inhibition titre in fraction 1 is not an accurate measure of the total rubellaspecific IgM antibody, part of which is present in fraction 2 and perhaps minimally in fraction 3. However, the antibody titre of this fraction can provide a satisfactory indication of the proportion of IgM relative to $\operatorname{IgA}$ and $\operatorname{IgG}$ antibody present in fractions 3 and 4. From the striking differences observed between sera from recently convalescent and immune persons, it appears that recent rubella infection can be diagnosed by measuring the antibody 
titre in fraction 1 of a single specimen of serum taken in the early convalescent stage. This pattern of antibody distribution after recent infection more or less follows that demonstrated previously in rubella by density-gradient centrifugation (Best et al, 1969) and in other bacterial and viral infections.

Neither of the other methods for demonstration of IgM antibody is entirely suitable for routine clinical use. By mercaptoethanol treatment, a twoand four-fold decrease in titre is only possible if the IgM antibody is a major portion of the total antibody. As a two-fold difference in haemagglutination inhibition titre in duplicate determinations is generally taken as the limit of experimental error, the sensitivity of mercaptoethanol treatment is quite limited. Sucrose density-gradient centrifugation is of a more specialized nature and requires the haemagglutination inhibition test to be done on several fractions and hypertonicity and viscosity interfere with erythrocyte settling patterns. Sephadex G-200 gel filtration, on the other hand, appears to provide a technique which is much more reliable than mercaptoethanol treatment, and technically much simpler than sucrose density-gradient centrifugation and immunofluorescence technique. The high proportion of haemagglutination inhibiting antibody in fraction 1 so clearly differentiates 'convalescent' sera from 'immune' sera that false negative results are unlikely to occur. The possibility of false-positive titres has been greatly decreased by dividing the IgM peak into fractions 1 and 2, as there is less likelihood of fraction 1 being contaminated with IgG. The principles involved in this successful application of Sephadex G-200 gel filtration to the

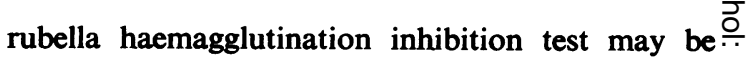
similarly used in the study of other viral infections.

We are indebted to ATN Channel 7, Sydney, for supporting one of us (J.D.G.) with a research fellowship.

References

Alford, C. A., Jr. (1965). Studies on antibody in congenital rubella $\vec{\circ}$ infections. Amer. J. dis. Child., 110, 455-463.

Banatvala, J. E., Best, J. M., Kennedy, E. A., Smith, E. E., and $\overrightarrow{\vec{G}}$ Spence, M. E. (1967). A serological method for demonstrating $\omega$ recent infection by rubella virus. Brit. med. J., 3, 285-287.

Baublis, J. V., and Brown, G. C. (1968). Specific responses of the immunoglobulins to rubella infection. Proc. Soc. exp. Biol. N
Med. (N.Y.), 128, 206-210.

Best, J. M., Banatvala, J. E., and Watson, D. (1969). Serum IgM $\sigma$ and IgG responses in postnatally acquired rubella. Lancet, $2, \mathrm{ir}$ 65-68.

Stewart, G. L., Parkman, P. D., Hopp, H. E., Douglas, R. D. Hamilton, J. P., and Meyer, H. M., Jr. (1967). Rubella virus haemagglutination inhibition test. New Engl. J. Med., 276, 554-557.

Vesikari, T., and Vaheri, A. (1968). Rubella: a method for rapid $\mathbb{D}$ diagnosis of a recent infection by demonstration of the IgMO antibodies. Brit. med. J., 1, 221-223.

\section{Addendum}

In subsequent experiments, we have used HEPES buffer without albumin as eluent in Sephadex G-200 fractionation and formalinized sheep erythrocytes in the haemagglutination-inhibition test (Gupta and Peterson, 1971). Appl. Microbiol. The IgM antibody in fraction 1 was also found to be completely reduced on treatment of this fraction with $0 \cdot 2 \mathrm{M}$ mercapto- 0 ethanol. Such treatment can, therefore, be used to 2 confirm further the IgM nature of the antibody in $\overline{\bar{o}}$ fraction 1.

Gupta, J. D., and Peterson, V. J. (1971). Appl. Microbiol., 21, 749750. 